\title{
Energy Management of Automobile Exhaust Thermoelectric Hybrid Power Based on Maximum Power Point Tracking and Fuzzy Logic Control
}

\author{
Rui Quan ${ }^{1,2, a}$, Guangyin Liu, ${ }^{1, b}$, Wei Zhou ${ }^{1, \mathrm{c}}$ and Liang Huang ${ }^{3, \mathrm{~d}}$ \\ ${ }^{1}$ Agricultural Mechanical Engineering Research and Design Institute, Hubei University of \\ Technology, Wuhan, China \\ ${ }^{2}$ Collaborative Innovation Center of Southern Agriculture Machinery and Equipment, Hubei \\ University of Technology, Wuhan, China \\ ${ }^{3}$ School of Automation, Wuhan University of Technology, Wuhan, China

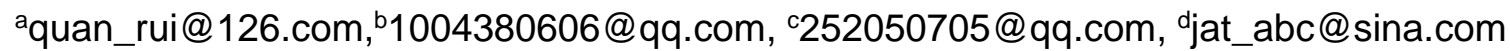

\begin{abstract}
Keywords: Automobile exhaust thermoelectric generator, hybrid power, energy management, maximum power point tracking, fuzzy logic control

Abstract. To enhance the output performance of automobile exhaust thermoelectric hybrid power, all the components such as engine, automobile exhaust thermoelectric generator (AETEG), DC/DC converter and batteries were modelled with ADVISOR, the maximum power point tracking (MPPT) method of AETEG combining perturb \& observe $(\mathrm{P} \& \mathrm{O})$ algorithm, quadratic interpolation and constant voltage tracking method was put forward in the power output process of AETEG, and the energy management was optimized with fuzzy logic control according to the state of charge (SOC) of batteries and external load power requirements. The simulated results demonstrate that the output power of automobile exhaust thermoelectric hybrid power well meets the requirements of external load consumed power during the urban dynamo driving schedule (UDDS), the SOC of batteries remains steady between 0.5 and 0.7 , and the maximum exhaust waste heat recovery efficiency of AETEG is about $1.3 \%$, validating the proposed energy management strategy as both feasible and efficient.
\end{abstract}

\section{Introduction}

The utilization efficiency of fossil fuel energy in internal combustion engine of vehicle is below $30 \%$, while nearly $40 \%$ of the rest one is directly wasted from exhaust [1]. Recovery of the exhaust heat based on thermoelectric modules (TEMs) has been a promising research to date [2], for the automobile exhaust thermoelectric hybrid power can improve the overall efficiency of internal combustion engine by applying the generated power in the vehicle's electric bus, and decreasing fuel consumption and reducing environmentally harmful emissions to some extent [3].

Due to the soft output characteristic of automobile exhaust thermoelectric generator (AETEG), i.e., its output voltage drops as its output current increases, its maximum power is affected by its output voltage and external resistance, DC/DC converter is implemented to interfaced its output with the external load, the automobile exhaust thermoelectric hybrid power is a markedly nonlinear system which is consist of the AETEG, DC/DC converter and batteries. According to the different power requirements of the external load and the state of charge (SOC) of batteries, how to optimize the energy management between AETEG and batteries is important to enhance the overall efficiency of automobile exhaust thermoelectric hybrid power.

\section{Automobile exhaust thermoelectric hybrid power}

The schematic diagram of the designed exhaust thermoelectric hybrid power is shown in Fig.1, it is composed of AETEG, DC/DC converter and batteries. For the AETEG, the engine coolant is implemented to control the cold side temperatures of TEMs, the cold sides of four TEMs of each row in a layer are fixed with a common small cooling box, and eight cooling boxes of each layer compose 
a whole cooling unit [4]. The inlet of heat exchanger is connected to the outlet of engine, due to the non-uniform temperature distribution of heat exchanger, once its surface temperature approaches the maximum operating temperature of a certain single thermoelectric module (TEM), exhaust is directly bypassed to the catalytic converter to protect them.

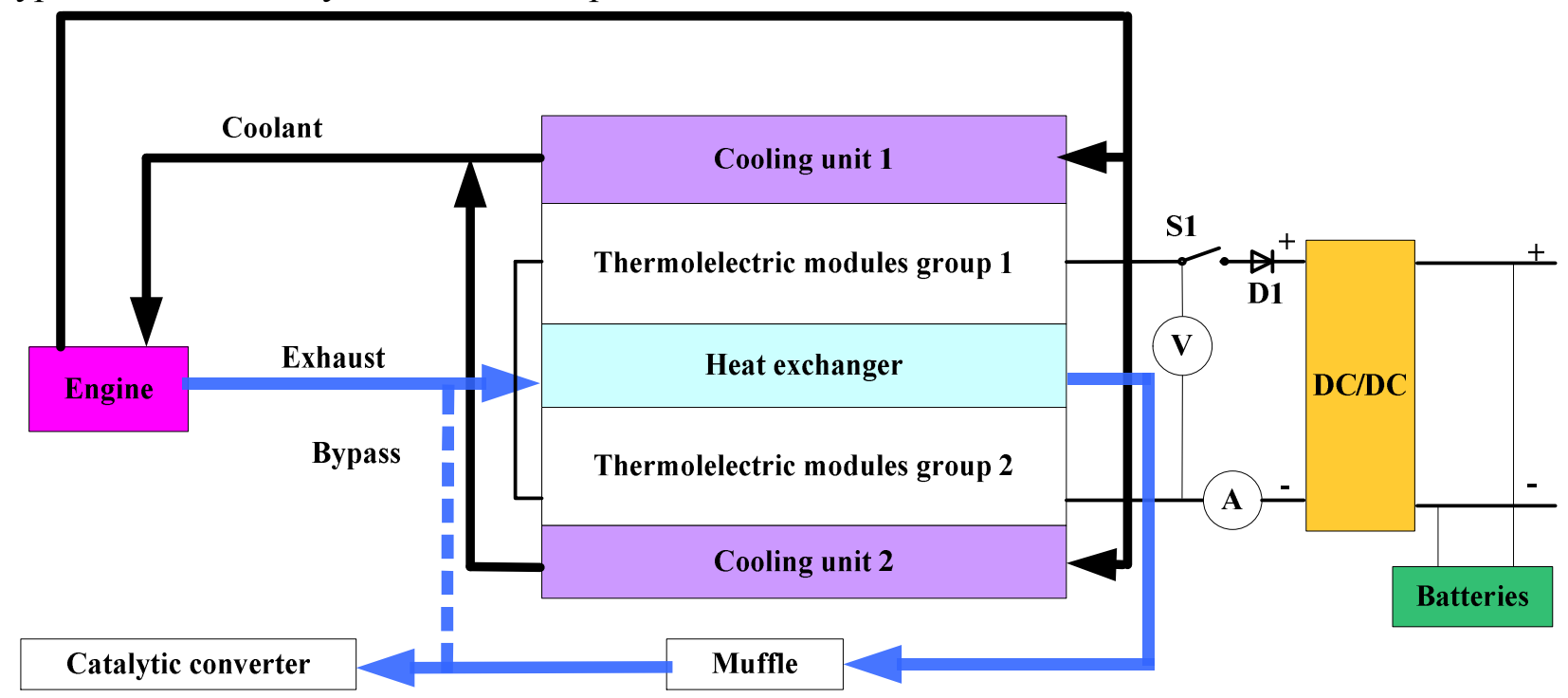

Fig.1 Schematic of the designed automobile exhaust thermoelectric hybrid power

For TEMs group 1, the number of TEMs is from 1 to 32, while the number of single TEMs in group 2 is from 33 to 64, all the TEMs are connected in series as the whole output of AETEG. Different interior flow cavities of heat exchangers, different surface temperature distribution and performance of TEMs. There are a series of dummy plates at both sides of the heat exchanger's interior cavity, here called the herring-bone structure [5]. The effective heat conduction length is 400 $\mathrm{mm}$, the effective width is $280 \mathrm{~mm}$, the exterior height is $18 \mathrm{~mm}$, the interior thickness is $2 \mathrm{~mm}$, and it is made of brass.

\section{Energy management modes}

To optimize the energy management of the automobile exhaust thermoelectric hybrid power, it is crucial to ensure AETEG works at its maximum power point so that the power generation potentials of all the TEMs can be fully exploited, and the SOC of batteries maintain within a safe range in case of overcharge or over-discharge. During different driving cycles, the power requirements of exterior load vary accordingly, it is essential to manage the energy distribution according to the real time maximum output performance of AETEG (denoted $P_{\max }$ ), SOC of batteries (denoted $B_{s o c}$ ) and power requirements of exterior load (denoted $\left.P_{\text {load }}\right)$. As shown in Fig.2, there are four typical kinds of energy management modes: case (a), $P_{\max }>P_{\text {load }}, B_{\text {soc }} \leq 0.3$; case (b), $P_{\max }>P_{\text {load }}, \boldsymbol{B}_{\text {soc }}>0.3$; case (c), $P_{\max }<$ $P_{\text {load }}, B_{\text {soc }}>0.3$; case (d), $P_{\max }<P_{\text {load }}, B_{\text {soc }} \leq 0.3$.

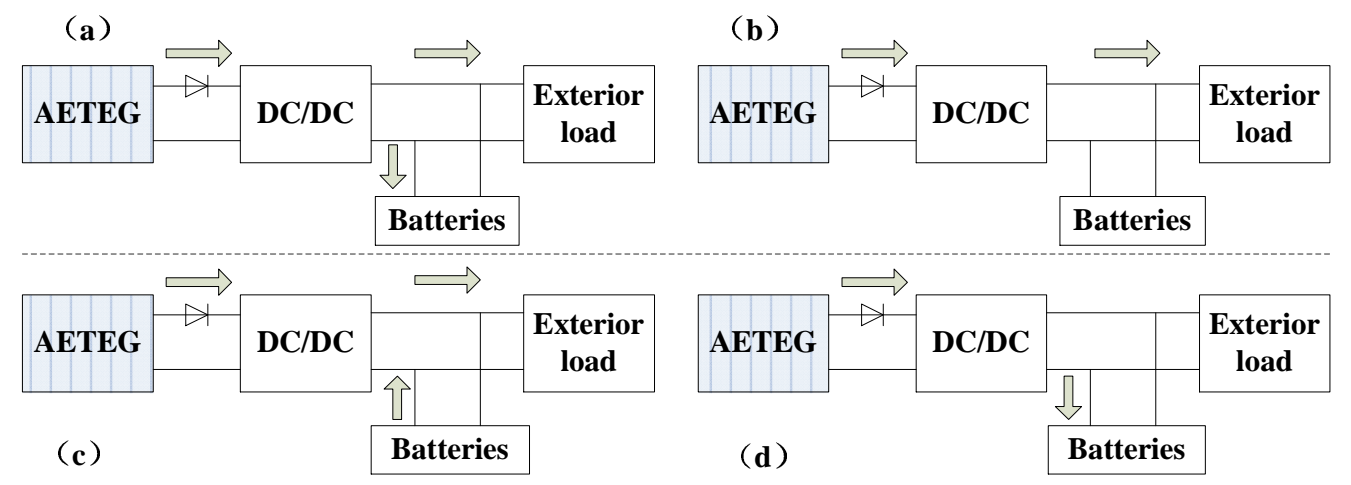

Fig.2 Energy management modes of automobile exhaust thermoelectric hybrid power 


\section{Maximum power point tracking of AETEG}

The output character of AETEG is soft, and its output power is mainly affected by the external load resistance and the temperature difference for given engine operation conditions. Thus, the maximum power point tracking (MPPT) of AETEG is very important to enhance the overall efficiency of the automobile exhaust thermoelectric hybrid power. There have been lots of maximum power point tracking (MPPT) algorithms applied in power generation system so far, such as constant voltage method, perturb \& observe (P\&O) algorithm, quadratic interpolation algorithm, incremental conductance (INC) algorithm, intermittent scanning, fuzzy control method, etc. In this section, a hybrid MPPT algorithm is adopted. Firstly, it searched the maximum power point with P\&O algorithms and quadratic interpolation method, then, it forced the AETEG to work at its maximum power point with constant voltage tracking [6].

\section{Energy control strategy}

Fuzzy logic control is a good way to manage the energy flow between AETEG and batteries, for it does not need precise mathematical models. The proposed energy control strategy of automobile exhaust thermoelectric hybrid power is shown in Fig.3. $T_{\mathrm{H}}$ and $T_{\mathrm{L}}$ denote the average hot side and cold side temperature of TEMs, $\Delta P$ denotes the difference between $P_{\text {max }}$ and $P_{\text {load }}, P_{b a t}$ and $P_{A E T E G}$ denote the real-time output power of batteries and AETEG, $D$ denotes the duty cycle of switching tube used in DC/DC converter. Firstly, the maximum power of AETEG is estimated according to the engine speeds and torques. Then, $\Delta P$ is evaluated, and the power distribution coefficient (denoted $\lambda$ ) is controlled by fuzzy logic controller with the inputs of $\Delta P$ and estimated SOC value. Finally, the real maximum power of AETEG is tracked with the proposed MPPT method, the power distribution between $P_{b a t}$ and $P_{A E T E G}$ is revised, and the switching tube's duty cycle is adjusted accordingly.

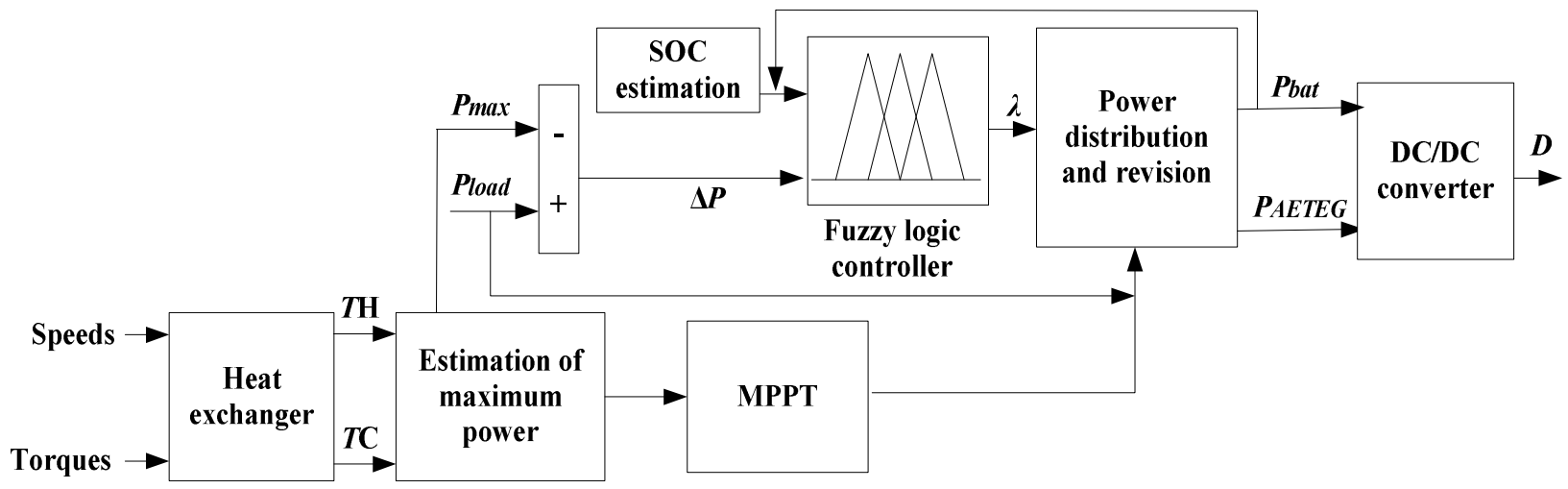

Fig.3 Energy control strategy based on fuzzy logic
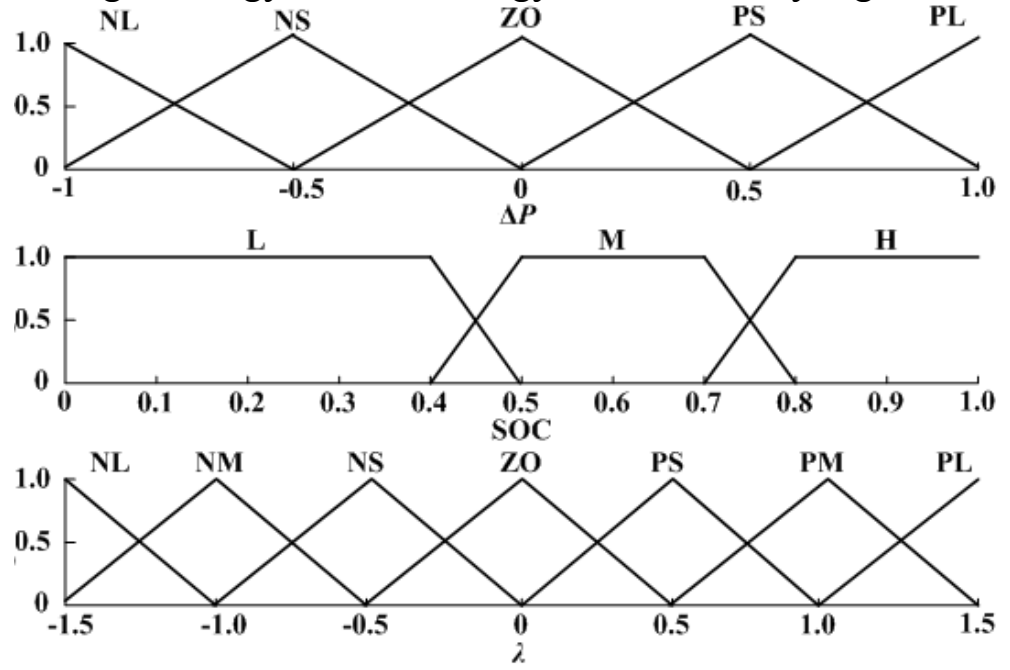

Fig.4 Membership functions 
For the fuzzy logic control, the adopted fuzzy sets of $\Delta P$, SOC and $\lambda$ are $\{N L, N S, Z O, P S, P L\},\{L$, $\mathrm{M}, \mathrm{H}\}$ and $\{\mathrm{NL}, \mathrm{NM}, \mathrm{NS}, \mathrm{ZO}, \mathrm{PS}, \mathrm{PM}, \mathrm{PL}\}$, and their domains of discourse are $[-1,1],[0,1]$ and $[-1.5,1.5]$, respectively. NL denotes negatively large, NM denotes negatively middle, NS denotes negatively small, NO denotes zero, PS denotes positively small, PM denotes positively middle, PL denotes positively large, $\mathrm{L}$ denotes low, $\mathrm{M}$ denoted middle, $\mathrm{H}$ denotes high. According to expert's experience, the membership functions of $\Delta P$, SOC and $\lambda$ are shown in Fig.4, and the corresponding fuzzy control rules are shown in Table 1.

Table 1. Fuzzy control rules

\begin{tabular}{|c|c|c|c|c|c|}
\hline \multirow{2}{*}{ SOC } & \multicolumn{5}{|c|}{$\Delta P$} \\
\cline { 2 - 6 } & NL & NS & ZO & PS & PL \\
\hline L & NS & ZO & PS & PM & PL \\
\hline M & NM & NS & ZO & PS & PM \\
\hline H & NL & NM & NS & ZO & PS \\
\hline
\end{tabular}

\section{Simulation and analysis}

Based on a certain vehicle, the simulated parameters of both vehicle and automobile exhaust thermoelectric hybrid power are shown in Table 2. There are eight single lithium iron phosphate batteries in series, and their open circuit voltages, maximum voltages and minimum voltages are set in the NIMH6 named file. There have been several popular driving cycles widely used in the vehicle performance tests, such as urban dynamometer driving schedule (UDDS), economic commission for Europe (ECE) plus extra urban driving cycle (EUDC) and highway fuel economy test (HWFET), in view of representativeness and typicality, as shown in Fig.5, UDDS is adopted in this section.

Table 2. Parameters of hybrid power system

\begin{tabular}{|c|c|c|}
\hline \multirow{2}{*}{ Name } & \multicolumn{2}{|c|}{ Parameters } \\
\hline \multirow{3}{*}{ Vehicle } & Size: $4717 \mathrm{~mm} \times 2210 \mathrm{~mm} \times 1983 \mathrm{~mm}$ & Windward area: $5.17 \mathrm{~m}^{2}$ \\
\cline { 2 - 3 } & Total weight: $3500 \mathrm{~kg}$ & Rolling resistance coefficient: 0.0135 \\
\cline { 2 - 3 } Engine & Wheel rolling radius: $0.37 \mathrm{~m}$ & Wind resistance coefficient: 0.65 \\
\cline { 2 - 3 } & Capacity: $3.9 \mathrm{~L}$ & Rated power: $112 \mathrm{~kW}(2700 \mathrm{rpm})$ \\
\hline \multirow{2}{*}{ AETEG } & TEMs dimensions:56mm $\times 56 \mathrm{~mm} \times 6 \mathrm{~mm}$ & Maximum speed: $3000 \mathrm{rpm}$ \\
\cline { 2 - 3 } & TEMs number: 64 & Type: $\mathrm{Bi}_{2}$ Te 3 modules \\
\hline \multirow{2}{*}{$\begin{array}{c}\text { Lithium } \\
\text { batteries }\end{array}$} & Maximum discharge rate: $5 \mathrm{C}$ & Rated voltage: $25 \mathrm{~V}$ \\
\cline { 2 - 3 } $\begin{array}{c}\text { DC/DC } \\
\text { converter }\end{array}$ & Topology: Buck & SOC range: $30 \% \sim 80 \%$ \\
\cline { 2 - 3 } & Input voltage: $70 \mathrm{~V} \sim 400 \mathrm{~V}$ & Average efficiency: $95 \%$ \\
\hline
\end{tabular}

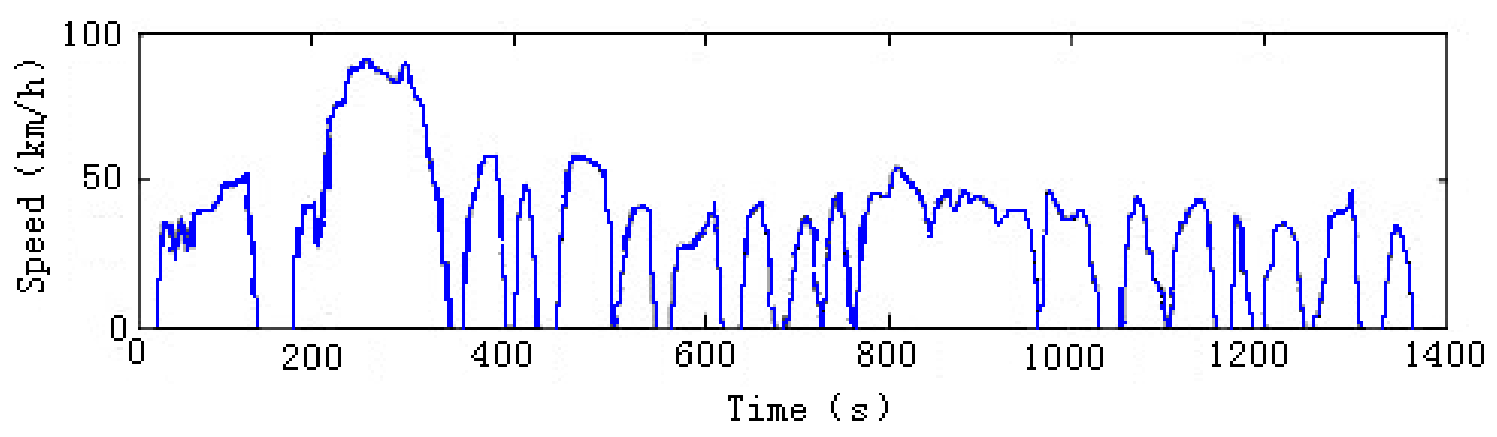

Fig.5 UDDS driving cycle 
Based on the given external load consumed power and UDDS, and according to the designed energy control strategy above, the real time energy distribution of AETEG and batteries based on the power demand of external load is shown in Fig.6.

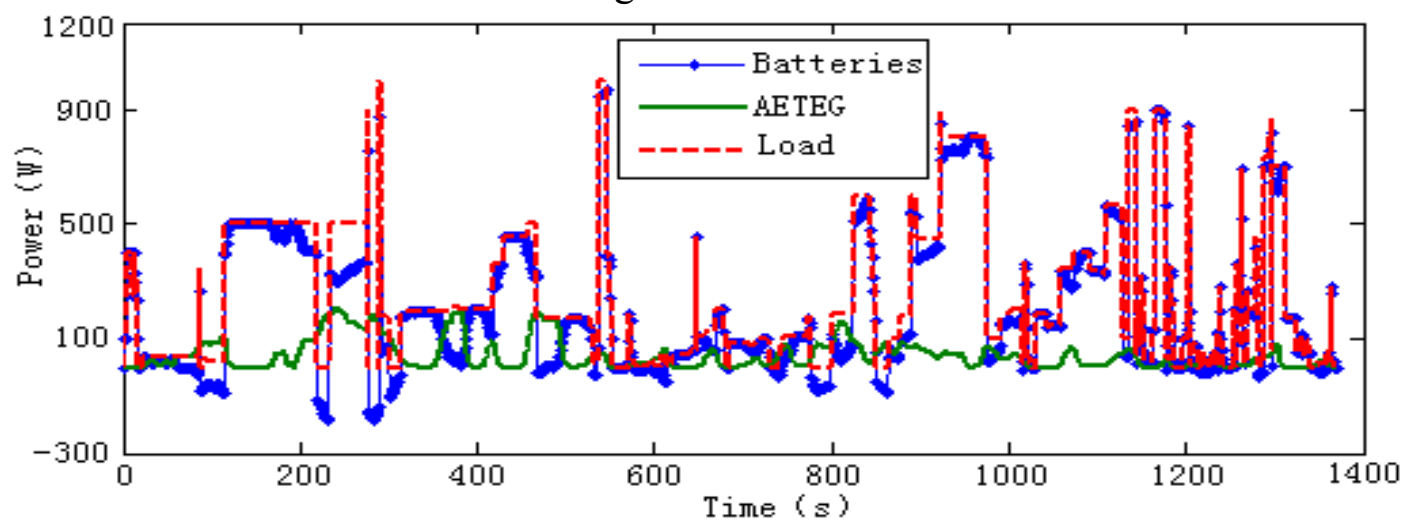

Fig.6 The energy distributions of the hybrid power

For the batteries, the positive power means discharge, while the negative power represents charge. It can be concluded that the output power of both AETEG and batteries meets the power requirements of external load. In addition, the corresponding SOC of batteries is shown in Fig.7, it maintains relatively steady during UDDS, which also meets the control requirements well.

Furthermore, according to the heat balance descriptions of AETEG [7] and the presentation of a recent case study [8], supposing the exhaust gas energy at the outlet of heat exchanger account for $45 \%$ of the total exhaust heat, while another $45 \%$ is represented in the heat lost from the leg-sides of the TEMs by convection and radiation, the heat lost by conduction in the TEMs due to thermal contact resistance, and the effective heat transferred through TEMs together, the corresponding maximum waste heat recovery efficiency of AETEG during UDDS is shown in Figure.8. The maximum waste heat recovery efficiency of AETEG relatively decreases as the speeds of engine increase, it is $1.3 \%$ based on $64 \mathrm{Be}_{2} \mathrm{Ti}_{3}$ TEMs with the maximum generation efficiency being $5 \%$, which illustrates that much more exhaust heat is lost with form of non-used zones of heat exchanger by radiation and convection, leg-sides of the TEMs by convection and radiation, gaps between the TEMs as the output power and speeds of engine increase.

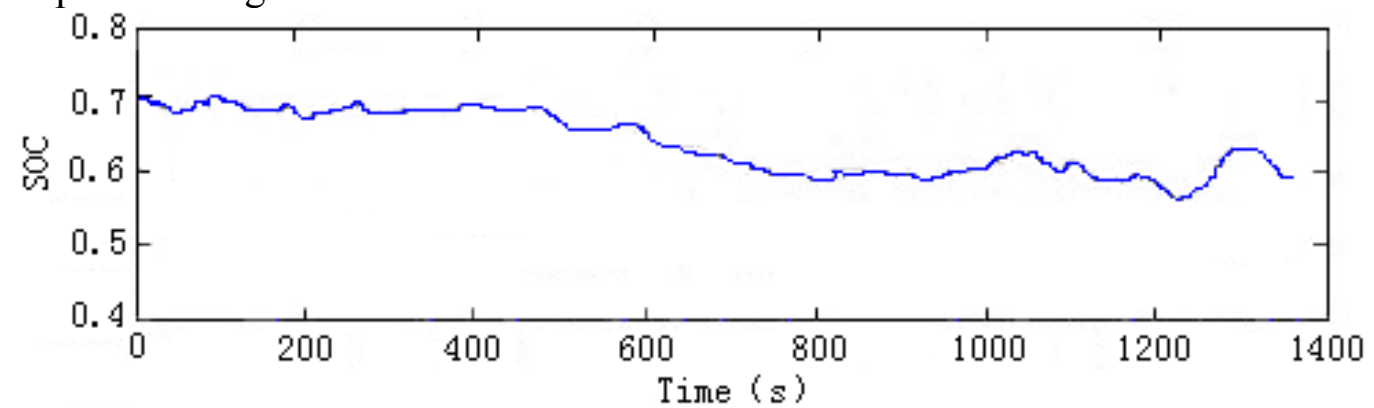

Fig.7 SOC of batteries

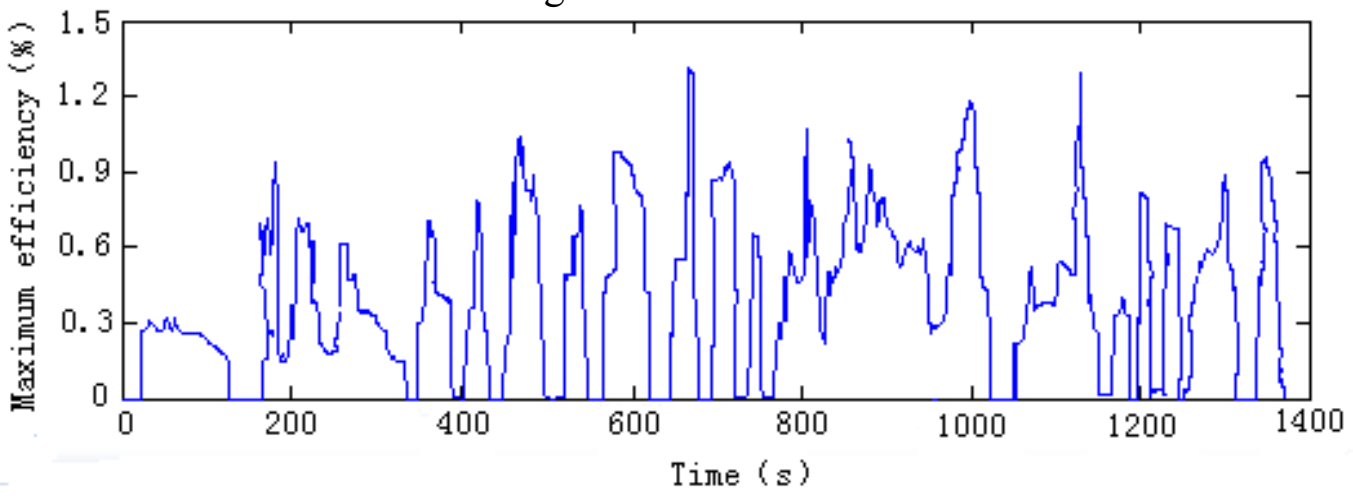

Fig. 8 The maximum efficiency of AETEG 


\section{Conclusions}

The vehicle electric bus application of AETEG in further will be a research focus even if the development of AETEG is in the initial stage, for it can improve the fuel economy of vehicle by recycling the exhaust waste heat. Due to the soft output characteristic, it is important to control the energy distribution between AETEG and batteries according to the required power of external load.ADVISOR is a good platform to set up the components models of vehicle, according to the modelling method, the automobile exhaust thermoelectric hybrid power was also modelled, and the MPPT algorithm and fuzzy logic control were implemented in its energy distribution. Both the simulated and experimental results validate that the adopted energy control strategy is feasible and efficient, as it can enhance the dynamic response and fuel economy performance.

\section{Acknowledgements}

This work was financially supported by National Natural Science Foundation of China (51407063) and Doctor Scientific Research Foundation of Hubei University of Technology (BSQD13064).

\section{References}

[1] S. Kim, S. Park, S. Kim and S.H. Rhi: J. Electron. Mater. Vol. 40(2011), p. 812-816.

[2] M.A. Karri, E.F. Thacher and B.T. Helenbrook: Energy. Convers. Manage. Vol. 52(2011), p. 1596-1611.

[3] M.E. Demir and I. Dincer: Appl. Therm. Eng. Vol. 120 (2017), p. 694-707.

[4] R. Quan, X.F. Tang, S.H. Quan and L. Huang: J. Electron. Mater. Vol. 42(2013), p. 1469-1475.

[5] X. Liu, Y.D. Deng, K. Zhang, M. Xu, Y. Xu and C.Q. Su: Appl. Therm. Eng. Vol.71 (2014), p. 364-370.

[6] R.Quan, W. Zhou, G.Y. Yang and S.H. Quan: J. Electron. Mater. Vol. 46(2016), p. 2676-2683.

[7] X.L.Gou, H. Xiao and S.W. Yang: Appl. Energy. Vol. 87(2010), p. 3131-3136.

[8] K.M. Saqr, M.K. Mansour and M.N. Musa: Int. J. Automot. Techn. Vol. 9(2008), p. 155-160. 